\title{
PENGARUH PENGGUNAAN FILTER PADA KNALPOT SEPEDA MOTOR UNTUK MENGURANGI TINGKAT EMISI GAS BUANG KENDARAAN
}

\author{
Novita Sari, M.Eng \\ Dosen STTD \\ J1. Raya Setu No. 89, Bekasi \\ Telp./Fax : (021) 8254640 \\ Dr. Made Suraharta, MT \\ Dosen STTD \\ J1. Raya Setu No. 89, Bekasi \\ Telp./Fax : (021) 8254640
}

\author{
Dani Hardianto, M.Sc \\ Dosen STTD \\ J1. Raya Setu No. 89, Bekasi \\ Telp./Fax : (021) 8254640
}

\begin{abstract}
Vehicles gas emissions are the most dominant factor causing air pollution, especially in large cities. Gas emissions produced by motor vehicles cause air pollution around 70-80 percent. Base on Central Statistics Agency in 2017, the proportion of motorcycle is $86 \%$ of the total of vehicles, $12 \%$ of passenger cars and $2 \%$ of buses. To reduce the increase in pollutant material is to use exhaust gas filters on vehicles. The utilization of installed gas filters in Indonesia is still limited to passenger cars while the proportion of motorcylce highest compared to other vehicles.

This research is a laboratory research with quantitative methods, where data analysis is used in this study to find out how much influence the utilization of filters on motorcyle exhaust to reduce the level of motorcycle gas emissions. To find out the value of motorcycle gas emissions, the instrument used is a gas analyzer. The filter material used is zeolite with a thickness variation of $5 \mathrm{~cm}, 10 \mathrm{~cm}$ and $13 \mathrm{~cm}$, this filter is installed on the motorcyle exhaust.

The result of the average $\mathrm{HC}$ and $\mathrm{CO}$ values, filters with a thickness of 10 $\mathrm{cm}$ are more effective than filters with a thickness of $5 \mathrm{~cm}$ and $13 \mathrm{~cm}$, with an average reduction in CO levels of $33 \%$ and $\mathrm{HC}$ by $44 \%$.
\end{abstract}

Keywords: Gas Emissions, Motor Cycle, Ziolite Filter 


\begin{abstract}
ABSTRAKSI
Emisi gas buang kendaraan bermotor merupakan faktor penyebab polusi udara yang paling dominan, terutama di kotakota besar. Emisi gas buang yang dihasilkan oleh kendaraan bermotor ini mengakibatkan polusi udara sekitar 70-80 persen. Dari data Badan Pusat Statistik pada tahun 2017, proporsi sepeda motor sebesar $86 \%$ dari total jenis kendaraan, $12 \%$ mobil penumpangg dan $2 \%$ Bis. Usaha untuk menanggulangi bertambahnya bahan polutan yaitu dengan menggunakan filter gas buang pada semua kendaraan bermotor. Penggunaan filter gas buang kendaraan bermotor di Indonesia belum begitu banyak karena masih terbatas pada mobil penumpaang sedangkan proporsi sepeda motor di jalan tertinggi dibandingkan kendaraan lainnya.

Penelitian ini merupakan penelitian laboratorium dengan metode kuantitatif, dimana analisis data yang digunakan dalam penelitian ini untuk mencari berapa besar pengaruh penggunaan filter pada knalpot kendaraan untuk mengurangi tingkat emisi gas buang sepeda motor. Untuk mengetahui nilai emisi gas buang sepeda motor, alat yang digunakan adalah gas analyzer. Bahan filter yang digunakan adalah zeolite dengan variasi ketebalan $5 \mathrm{~cm}, 10 \mathrm{~cm}$ dan $13 \mathrm{~cm}$, filter ini dipasang pada klanpot kendaraan.

Dari analisis rata-rata nilai $\mathrm{HC}$ dan $\mathrm{CO}$, filter dengan ketebalan $10 \mathrm{~cm}$ lebih efektif dibandingkan dengan filter dengan ketebalan $5 \mathrm{~cm}$ dan $13 \mathrm{~cm}$, dengan nilai penurunan rata-rata kadar CO sebesar $33 \%$ dan $\mathrm{HC}$ sebesar $44 \%$.
\end{abstract}

\title{
Kata Kunci : Emisi gas buang, Sepeda motor, filter ziolite
}

\section{PENDAHULUAN}

Emisi gas buang kendaraan bermotor merupakan faktor penyebab polusi udara yang paling dominan, terutama di kotakota besar. Emisi gas buang yang dihasilkan oleh kendaraan bermotor ini mengakibatkan polusi udara sekitar 70-80 persen. Dari data Badan Pusat Statistik pada tahun 2017, proporsi sepeda motor sebesar $86 \%$ dari total jenis kendaraan, $12 \%$ mobil penumpangg dan $2 \%$ Bis. Pada tahun 2018 dari data Mabes POLRI, jumlah kendaraan yang terdaftar di Indonesia pada mencapai 111 Juta, atau tepatnya 111.571.239 unit kendaraaan. Angka tersebut termasuk jumlah sepeda motor yang memberikan kontribusi terbesar sebesar 82\% atau 91.085.532 unit sepeda motor. Menurut Ketua Asosiasi Industri Sepeda Motor Indonesia (AISI), Gunadi Shindhuwinata, jumlah sepeda motor di Indonesia saat ini sebanyak 85 juta unit. "Saat ini populasi sepeda motor di 
Indonesia 85 juta unit. Dari jumlah masyarakat Indonesia yang sekira 250 jutaan, artinya satu banding tiga,"

Polusi udara akibat dari emisi gas buang kendaraan bermotor terus mengalami peningkatan. Bahan polutan tersebut biasanya berupa Gas Carbon Monoksida (C0), Carbon Dioksida $\left(\mathrm{CO}_{2}\right)$ Hidrokarbon (HC), Nitorgen Oksida (NOx), Sulfir Oksida $\left(\mathrm{SO}_{2}\right)$ dan Timbal $(\mathrm{Pb})$. Pengaruh buruk akibat bahan polutan yang tidak terkendali adalah pemicu terhadap pemanasan global dan penyebab penyebaran berbagai gannguan kesehatan pada manusia. Gas buang kendaraan ini memiliki dampak negatif bagi kesehatan, kerugian yang ditimbulkan yaitu:

1. Pemicu hipertensi

2. Penyebab iritasi mata

3. Penurunan kecerdasan otak

4. Mengganggu perkembangan mental anak

5. Tenggorokan gatal dan batuk-batuk

6. Mengurangi fungsi reproduksi laki-laki.

Usaha untuk menanggulangi bertambahnya bahan polutan yaitu dengan menggunakan filter gas buang pada semua kendaraan bermotor. Penggunaan filter gas buang kendaraan bermotor di Indonesia belum begitu banyak karena masih terbatas pada mobil penumpaang sedangkan proporsi sepeda motor di jalan tertinggi dibandingkan kendaraan lainnya.

\section{Tujuan Penelitian}

Tujuan dari penelitian penelitian tentang Pengaruh Penggunaan Filter pada knalpot sepeda motor untuk mengurangi tingkat Emisi Gas Buang Kendaraan adalah:

a. Mengetahui nilai emisi gas buang sepeda motor

b. Mendesain alat filter untuk mengurangi tingkat emisi gas buang sepeda motor

c. Mencari berapa besar pengaruh penggunaan filter pada knalpot kendaraan dalam mengurangi tingkat emisi gas buang sepeda motor 


\section{Metodologi Penelitian}

Penelitian ini dilaksanakan di Laboratorium Pengujian Kendaraan Bermotor Sekolah Tinggi Transportasi Darat. Secara garis besar alur penelitian dapat dilihat pada Gambar 3.1

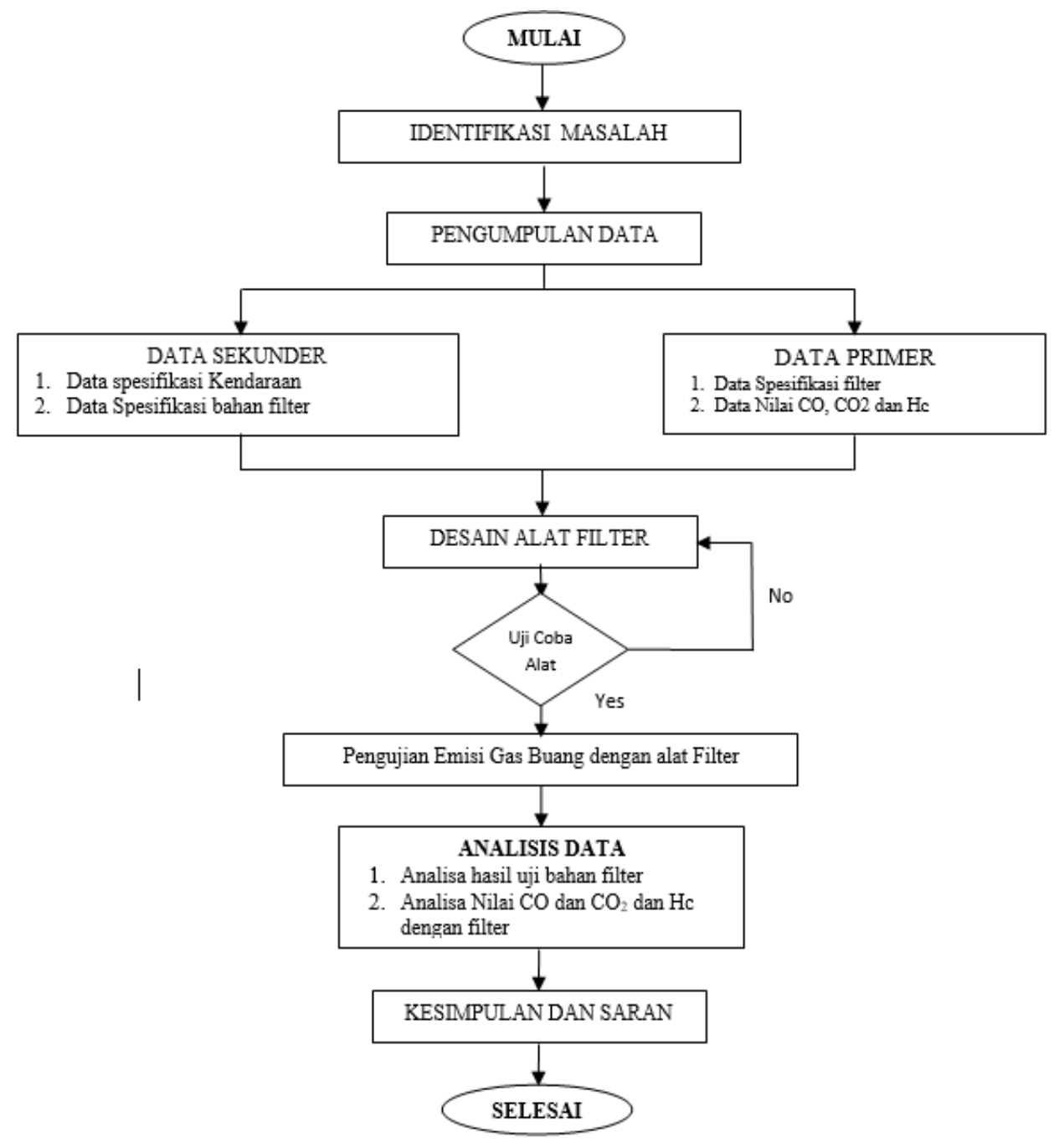

Gambar 1 Bagan Alir Penelitian

Penelitian ini merupakan penelitian laboratorium dengan metode kuantitatif, dimana analisis data yang digunakan dalam penelitian ini untuk mencari berapa besar pengaruh penggunaan filter pada knalpot kendaraan untuk mengurangi tingkat emisi gas buang sepeda motor. Untuk mengetahui nilai emisi gas buang sepeda motor, alat yang digunakan adalah gas analyzer. Bahan filter yang 
digunakan adalah zeolite dengan variasi ketebalan $5 \mathrm{~cm}, 10 \mathrm{~cm}$ dan $13 \mathrm{~cm}$, filter ini dipasang pada klanpot kendaraan.

Analisis data yang digunakan dalam penelitian ini adalah untuk mencari berapa besar pengaruh penggunaan filter pada knalpot kendaraan untuk mengurangi tingkat emisi gas buang sepeda motor.

\section{Metode Pengumpulan Data}

Dalam penelitian ini, dibutuhkan data-data untuk keperluan analisis yang diperoleh dari data sekunder dan data primer.

1. Data sekunder, yang dibutuhkan untuk mendukung sebagai bahan analisis dalam penelitian ini antara lain data teknis spesifikasi kendaraan dan data spesifikasi bahan filter yang digunakan sebagai benda uji

2. Data primer, yang dibutuhkan dalam penelitian ini antara lain:

a. Data hasil uji emisi gas buang sepeda motor tanpa filter, yaitu dilakukan dengan cara menguji emisi gas buang sepeda motor secara langsung dengan menggunakan alat Gas Analyzer.

b. Data hasil uji bahan filter, yaitu dengan melakukan uji bahan alat filter yang digunakan secara uji laboratorium kimia untuk mengetahui komposisi dasar dari bahan filer.

c. Data hasil uji emisi gas buang sepeda motor dengan filter, yaitu dilakukan dengan cara menguji emisi gas buang sepeda motor secara langsung setelah menggunakan filter dengan menggunakan alat Gas Analyzer.

\section{ANALISIS DAN PEMBAHASAN}

1. Hasil Uji Pendahuluan

Sebelum benda uji digunakan dalam penelitian dilakukan terlebih dahulu uji pendahuluan yang bertujuan untuk mengetahui sifat fisik dan mekanis dari benda uji yang digunakan. Bahan utama Filter dalam penelitian ini adalah pasir zeolite yang lolos saringan Mesh 16, yaitu pasir dengan ukuran butiran 1,1 mm.

Dari hasil pengujian sifat fisik pasir zeolite di laboratorium di dapat nilai-nilai pada Tabel 1 
Tabel 1 Hasil Uji Sifat Fisik Pasir Zeolite

\begin{tabular}{|c|l|c|}
\hline No & \multicolumn{1}{|c|}{ Sifat Fisik } & Nilai \\
\hline 1 & Berat Jenis & 2,04 \\
\hline 2 & Kadar Air Jenuh & $5,52 \%$ \\
\hline 3 & $\begin{array}{l}\text { Derajat } \\
\text { Kejenuhan }\end{array}$ & $35,06 \%$ \\
\hline 4 & Porositas & $11,26 \%$ \\
\hline 5 & Void Ratio & 0,13 \\
\hline
\end{tabular}

Dari hasil pengujian sifat mekanik pasir zeolite di laboratorium di dapat nilai-nilai pada Tabel 2

Penentuan sifat mekanik pasir zeolite dilakukan dengan uji tekan dan uji tarik yang merupakan uji merusak (destructive test).

a. Kuat Tekan

Tujuan utama dari pengujian kuat tekan uniaksial adalah untuk mendapatkan nilai kuat tekan dari benda uji. Nilai tegangan pada saat benda uji hancur didefinisikan sebagai kuat tekan uniaksial yang diformulakan oleh hubungan:

$$
\sigma=\frac{F}{A}
$$

Keterangan :

$\sigma \mathrm{c}=$ Kuat tekan uniaksial batuan $(\mathrm{MPa})$

$\mathrm{F}$ = Gaya yang bekerja pada saat contoh batuan hancur $(\mathrm{kN})$

A = Luas penampang awal contoh batuan yang tegak lurus arah gaya $(\mathrm{mm})$

\section{b. Kuat Geser}

Sifat mekanik pasir zeolite yang diperoleh dari hasil pengujian adalah kuat tarik $\left(\sigma_{\underline{t}}\right)$. Ada dua metode yang dapat dipergunakan untuk mengetahui kuat tarik benda uji di laboratorium, yaitu metode kuat tarik langsung dan metode kuat tarik tak langsung. Metode kuat tarik tak langsung merupakan pengujian yang paling sering digunakan. Hal ini disebabkan pengujian ini lebih mudah dan murah daripada pengujian kuat tarik langsung. Salah satu pengujian kuat tarik 
tak langsung adalah Brazilian test. Pada pengujian Brazilian, kuat tarik benda uji dapat ditentukan berdasarkan persamaan:

$$
\sigma t=\frac{F}{(D \times L)}
$$

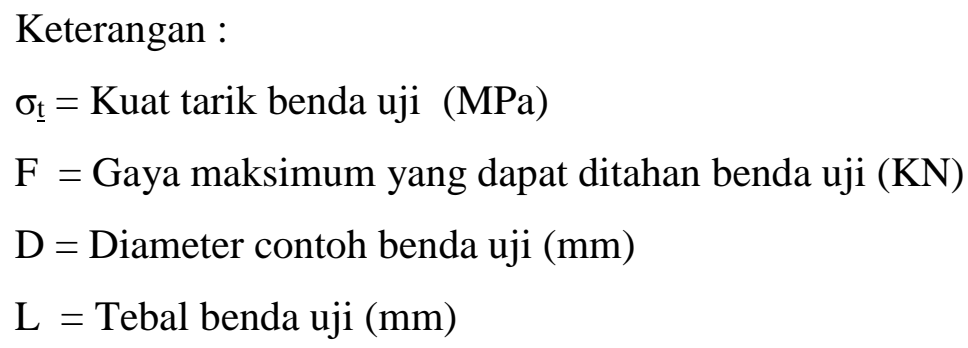

Tabel 2 Hasil Uji Sifat Mekanik Pasir Zeolite

\begin{tabular}{|r|l|r|}
\hline No & \multicolumn{1}{|c|}{ Sifat Mekanik } & \multicolumn{1}{c|}{ Nilai } \\
\hline 1 & Kuat Tekan & $609,17 \mathrm{~kg} / \mathrm{cm}^{2}$ \\
\hline 2 & Kuat Geser & $10 \mathrm{~kg} / \mathrm{cm}^{2}$ \\
\hline
\end{tabular}

2. Desain dan Setting up Benda Uji

Benda uji yang digunakan dalam penelitian ini adalah tiga unit sepeda motor dengan variant ketebalan filter $5 \mathrm{~cm}, 10 \mathrm{~cm}$ dan $13 \mathrm{~cm}$. Dalam pengujian emisi gas buang digunakan gas analyzer untuk mengetahui nilai emisi gas buang sepeda motor. Sepeda motor yang digunakan berbahan bakar bensin dengan kualifikasi umur sepeda motor dibawah 5 tahun. Masing variasi umur diambil 3 unit sepeda motor sebagai sample yang akan dipasang filter. Bahan filter yang digunakan adalah pasir zeolite yang didesain khusus agar bisa dipasang pada ujung sistem pembuangan gas sepeda motor.

Tabel 3 Spesifikasi Sepeda Motor yang digunakan sebagai Benda Uji

\begin{tabular}{|c|c|c|c|}
\hline Benda Uji & Motor 1 & Motor 2 & Motor 3 \\
\hline Jenis Motor & HONDA PCX & YAMAHA NMAX & AEROX \\
\hline Tahun Pembuatan & 2018 & 2018 & 2018 \\
\hline Transmisi & Automatic & Automatic & Automatic \\
\hline cc & 155 & 155 & 155 \\
\hline
\end{tabular}




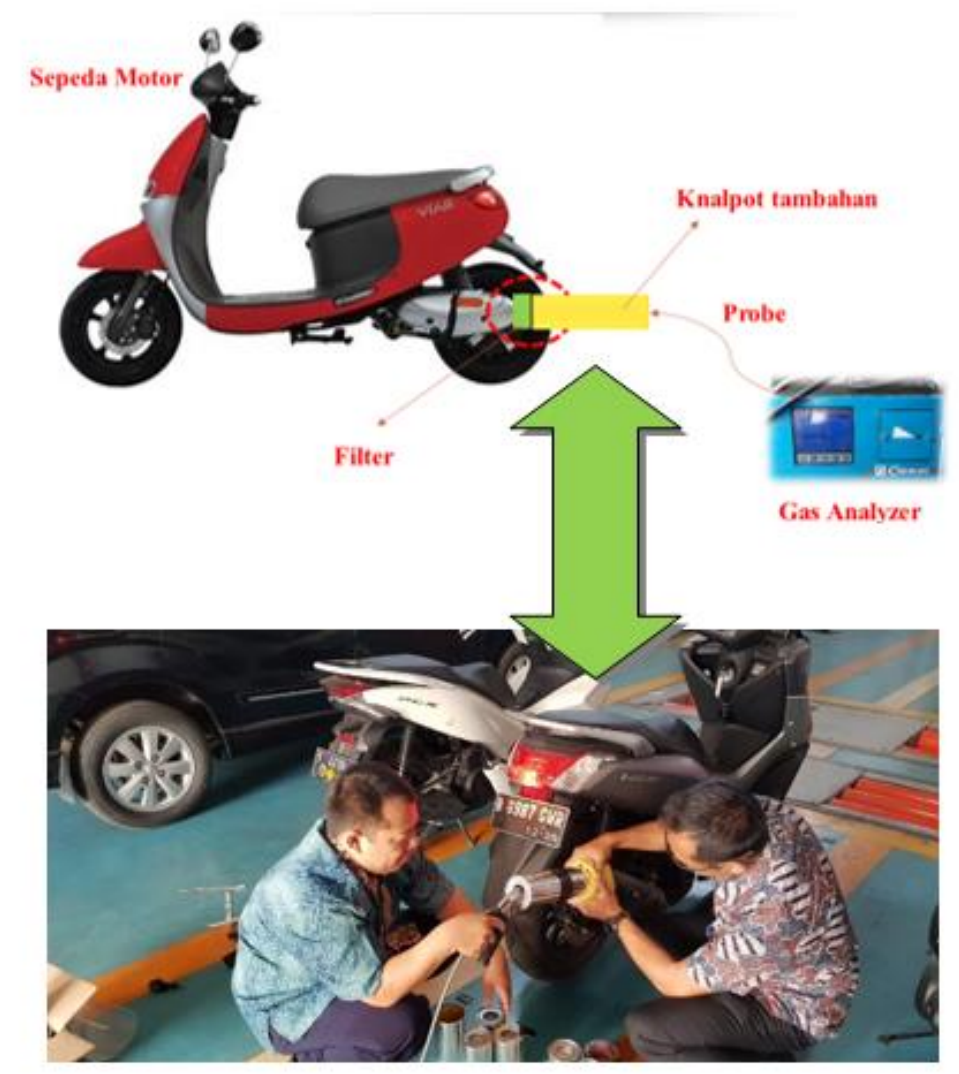

Gambar 2 Setting Up Pengujian Filter pada Sepeda Motor

\section{Analisis Hasil Pengujian Emisi}

Pengujian emisi gas buang dilaksanakan di laboratorium Pengujian Kendaraan Bermotor Sekolah Tinggi Transportasi Darat, dengan menggunakan sampel 3 unit sepeda motor yang di uji dengan metode Idle. Data dikumpulkan dengan melakukan tiga kali pengujian emisi gas buang setelah melewati filter zeolite ukuran mesh 16 dengan tiga variasi ketebalan filter.

Tabel 4 Hasil Pengujian Emisi Gas Buang Tanpa Filter

\begin{tabular}{|l|c|c|c|}
\hline \multicolumn{1}{|c|}{ Variabel } & Motor 1 & Motor 2 & Motor 3 \\
\hline CO (\% vol) & 0.3 & 0.36 & 0.47 \\
\hline CO2 (\% vol) & 6.6 & 6.7 & 8.8 \\
\hline HC (PPN VOL) & 122 & 171 & 300 \\
\hline O2 (\% vol) & 10.8 & 10.7 & 7.8 \\
\hline LAMBDA & 2.06 & 2.01 & 1.54 \\
\hline
\end{tabular}


Data pengujian emisi gas buang tahap awal akan digunakan sebagai data komparasi terhadap hasil pengujian setelah menggunakan filter.

Tabel 5 Hasil Pengujian Filter Zeolite Ketebalan 5 cm

\begin{tabular}{|l|c|c|c|c|c|c|}
\hline \multirow{2}{*}{ Variabel } & \multicolumn{2}{|c|}{ Motor 1 } & \multicolumn{2}{c|}{ Motor 2 } & \multicolumn{2}{c|}{ Motor 3 } \\
\cline { 2 - 7 } & $\begin{array}{c}\text { Tanpa } \\
\text { Filter }\end{array}$ & $\begin{array}{c}\text { Filter } \\
\mathbf{5} \mathbf{~ c m}\end{array}$ & $\begin{array}{c}\text { Tanpa } \\
\text { Filter }\end{array}$ & $\begin{array}{c}\text { Filter } \\
\mathbf{5} \mathbf{~ c m}\end{array}$ & $\begin{array}{c}\text { Tanpa } \\
\text { Filter }\end{array}$ & $\begin{array}{c}\text { Filter } \\
\mathbf{5} \mathbf{~ c m}\end{array}$ \\
\hline CO (\% vol) & 0.3 & 0.15 & 0.36 & 0.45 & 0.47 & 0.38 \\
\hline CO2 (\% vol) & 6.6 & 4.20 & 6.70 & 8.03 & 8.80 & 7.83 \\
\hline $\begin{array}{l}\text { HC (PPN } \\
\text { VOL) }\end{array}$ & 122 & 81.67 & 171.00 & 148.67 & 300.00 & 221.00 \\
\hline O2 (\% vol) & 10.8 & 14.20 & 10.70 & 9.03 & 7.80 & 9.43 \\
\hline LAMBDA & 2.06 & 3.26 & 2.01 & 1.76 & 1.54 & 1.77 \\
\hline
\end{tabular}

Tabel 6 Hasil Pengujian Filter Zeolite Ketebalan 10 cm

\begin{tabular}{|l|c|c|c|c|c|c|}
\hline \multirow{2}{*}{ Variabel } & \multicolumn{2}{|c|}{ Motor 1 } & \multicolumn{2}{c|}{ Motor 2 } & \multicolumn{2}{c|}{ Motor 3 } \\
\cline { 2 - 7 } & $\begin{array}{c}\text { Tanpa } \\
\text { Filter }\end{array}$ & $\begin{array}{c}\text { Filter } \\
\mathbf{1 0} \mathbf{~ c m}\end{array}$ & $\begin{array}{c}\text { Tanpa } \\
\text { Filter }\end{array}$ & $\begin{array}{c}\text { Filter } \\
\mathbf{1 0} \mathbf{~ c m}\end{array}$ & $\begin{array}{l}\text { Tanpa } \\
\text { Filter }\end{array}$ & $\begin{array}{c}\text { Filter } \\
\mathbf{1 0} \mathbf{~ c m}\end{array}$ \\
\hline $\mathrm{CO}(\% \mathrm{vol})$ & 0.3 & 0.15 & 0.36 & 0.31 & 0.47 & 0.32 \\
\hline $\mathrm{CO} 2(\% \mathrm{vol})$ & 6.6 & 3.97 & 6.70 & 5.77 & 8.80 & 6.67 \\
\hline $\mathrm{HC}(\mathrm{PPN}$ & & & & & & \\
VOL $)$ & 122 & 69.67 & 171.00 & 96.67 & 300.00 & 166.00 \\
\hline O2 (\% vol) & 10.8 & 14.40 & 10.70 & 12.07 & 7.80 & 10.80 \\
\hline LAMBDA & 2.06 & 3.45 & 2.01 & 2.35 & 1.54 & 2.07 \\
\hline
\end{tabular}

Tabel 4.9 Hasil Pengujian Filter Zeolite Ketebalan $13 \mathrm{~cm}$

\begin{tabular}{|l|c|c|c|c|c|c|}
\hline \multirow{2}{*}{ Variabel } & \multicolumn{2}{|c|}{ Motor 1 } & \multicolumn{2}{c|}{ Motor 2 } & \multicolumn{2}{c|}{ Motor 3 } \\
\cline { 2 - 7 } & $\begin{array}{c}\text { Tanpa } \\
\text { Filter }\end{array}$ & $\begin{array}{c}\text { Filter } \\
\mathbf{5} \mathbf{~ c m}\end{array}$ & $\begin{array}{c}\text { Tanpa } \\
\text { Filter }\end{array}$ & $\begin{array}{c}\text { Filter } \\
\mathbf{5} \mathbf{~ c m}\end{array}$ & $\begin{array}{c}\text { Tanpa } \\
\text { Filter }\end{array}$ & $\begin{array}{c}\text { Filter } \\
\mathbf{5} \mathbf{~ c m}\end{array}$ \\
\hline CO $(\%$ vol $)$ & 0.3 & 0.34 & 0.36 & 0.34 & 0.47 & 0.23 \\
\hline CO2 (\% vol) & 6.6 & 9.97 & 6.70 & 6.97 & 8.80 & 4.60 \\
\hline $\begin{array}{l}\text { HC (PPN } \\
\text { VOL })\end{array}$ & 122 & 144.67 & 171.00 & 101.67 & 300.00 & 115.00 \\
\hline O2 (\% vol) & 10.8 & 6.43 & 10.70 & 10.50 & 7.80 & 13.60 \\
\hline LAMBDA & 2.06 & 1.42 & 2.01 & 2.06 & 1.54 & 2.93 \\
\hline
\end{tabular}




\section{KESIMPULAN}

Berdasarkan hasil pengujian di laboratorium terhadap penggunaan filter pada knalpot sepeda motor dan data yang didapatkan dari penelitian, maka dapat ditarik kesimpulan sebagai berikut:

1. Hasil dari pengujian emisi dengan menggunakan filter, untuk nilai $\mathrm{CO}$ dihasilkan oleh Motor 1 filter dengan ketebalan $5 \mathrm{~cm}$ dan $10 \mathrm{~cm}$ mengalami penurunan sebesar $49 \%$ dan $51 \%$, dan untuk filter dengan ketebalan $13 \mathrm{~cm}$ mengalami kenaikan sebesar 14\%. Untuk nilai CO dihasilkan oleh Motor 2 filter dengan ketebalan $5 \mathrm{~cm}$ mengalami kenaikan sebesar $25 \%$ sedangkan filter dengan ketebalan $10 \mathrm{~cm}$ dan $13 \mathrm{~cm}$ mengalami penurunan $14 \%$ dan $6 \%$. Nilai CO dihasilkan oleh Motor 3 filter dengan ketebalan $5 \mathrm{~cm}$ dan $10 \mathrm{~cm}$ mengalami penurunan sebesar $19 \%$ dan $33 \%$, dan untuk filter dengan ketebalan $13 \mathrm{~cm}$ mengalami kenaikan sebesar 52\%

2. Hasil dari pengujian emisi dengan menggunakan filter, untuk nilai $\mathrm{CO} 2$ dihasilkan oleh Motor 1 dengan ketebalan filter $5 \mathrm{~cm}$ dan $10 \mathrm{~cm}$ mengalami penurunan sebesar $36 \%$ dan 40\%, sedangkan untuk filter dengan ketebalan 13 $\mathrm{cm}$ mengalami kenaikan sebesar $51 \%$. Untuk nilai CO2 tertinggi dihasilkan oleh Motor 2 dengan ketebalan filter $5 \mathrm{~cm}$ dan $10 \mathrm{~cm}$ mengalami penurunan sebesar 20\% dan 14\%, sedangkan untuk filter dengan ketebalan $13 \mathrm{~cm}$ mengalami kenaikan sebesar 4\%. Sedangkan untuk nilai $\mathrm{CO} 2$ tertinggi dihasilkan oleh Motor 3 dengan ketebalan filter $5 \mathrm{~cm}, 10 \mathrm{~cm}$ dan $13 \mathrm{~cm}$ mengalami penurunan sebesar $11 \%, 24 \%$ dan $48 \%$.

3. Hasil dari pengujian emisi dengan menggunakan filter, untuk nilai $\mathrm{HC}$ dihasilkan oleh Motor 1 dengan ketebalan filter $5 \mathrm{~cm}$ dan $10 \mathrm{~cm}$ mengalami penurunan sebesar 33\% dan 43\%, sedangkan untuk filter dengan ketebalan 13 cm mengalami kenaikan sebesar 19\%. Untuk nilai HC dihasilkan oleh Motor 2 dengan ketebalan filter $5 \mathrm{~cm}$ dan $10 \mathrm{~cm}$ mengalami penurunan sebesar $13 \%$ dan $43 \%$, sedangkan untuk filter dengan ketebalan $13 \mathrm{~cm}$ mengalami kenaikan sebesar $41 \%$. Untuk nilai HC dihasilkan oleh Motor 2 dengan ketebalan filter $5 \mathrm{~cm} 10 \mathrm{~cm}$ dan $13 \mathrm{~cm}$ mengalami penurunan sebesar $26 \%, 45 \%$ dan $62 \%$ 
4. Hasil dari pengujian emisi dengan menggunakan filter, untuk nilai $\mathrm{O} 2$ dihasilkan oleh Motor 1 dengan ketebalan filter $5 \mathrm{~cm} 10 \mathrm{~cm}$ dan $13 \mathrm{~cm}$ mengalami kenaikan sebesar 31\%, 33\%, dan 40\%. untuk nilai O2 dihasilkan oleh Motor 2 dengan ketebalan filter $5 \mathrm{~cm} 10 \mathrm{~cm}$ dan $13 \mathrm{~cm}$ mengalami kenaikan sebesar 16\%, 13\%, dan 2\%. Sedangkan untuk nilai O2 dihasilkan oleh Motor 3 dengan ketebalan filter $5 \mathrm{~cm} 10 \mathrm{~cm}$ dan $13 \mathrm{~cm}$ mengalami kenaikan sebesar $21 \%, 38 \%$, dan $74 \%$.

5. Dari analisis rata-rata nilai $\mathrm{HC}$ dan $\mathrm{CO}$, filter dengan ketebalan $10 \mathrm{~cm}$ lebih efektif dibandingkan dengan filter dengan ketebalan $5 \mathrm{~cm}$ dan $13 \mathrm{~cm}$, dengan nilai penurunan rata-rata kadar CO sebesar 33\% dan HC sebesar $44 \%$.

Adapun saran-saran dalam penelitian ini adalah sebagai berikut :

1. Untuk penelitian lebih lanjut di desain alat filter dengan selubung yang lebih durable

2. Diperbanyak benda uji agar hasil yang di dapat lebih akurat

3. Pada saat pengujian diperlukan waktu yang lebih Panjang agar dapat memprediksi lifetime dari alat filter

4. Perlu diuji kinerja sepeda motor akibat dari pengaruh penggunaan filter 


\section{DAFTAR PUSTAKA}

Ahmad M, 2006, Manajemen Lalu Lintas Perkotaan, Beta Offset, Yogyakarta

Arends BPM \& Berenschot H,1980, Motor Bensin, translate of Benzinemotoren, Erlangga, Jakarta

Dahlan H, Pratama EJ, Odina M, 2016 Pengaruh Penggunaan Membran Keramik Berbasis Zeolit dan Gypsum terhadap Emisi Gas CO, NOx Kendaraan Bermotor, Jurnal Teknik Kimia No. 2, Vol. 22, April 2016 Jurusan Teknik Kimia, Fakultas Teknik Universitas Sriwijaya, Palembang

Ghafur A, Siswanto R, Pemanfaatan Fly Ash Batu bara dengan Aditif Kaolin sebagai Filter Gas Buang terhadap Emisi Gas Buang Sepeda Motor Satria FU 150, Jukung Jurnal Teknik Lingkungan, 4(1) :12-18,2018 p-ISSN : 24610437, e-ISSN : 2540-9131 Program Studi Teknik Mesin, Fakultas Teknik, Universitas Lambung Mangkurat, Banjar Baru

Ifa L, Akbar M, Ramli AF dan Wiyati L, 2018, Pemanfaatan Cangkang Kerang dan Cangkang Kepiting sebagai Adsorben Logam $\mathrm{Cu}, \mathrm{Pb}$ dan $\mathrm{Zn}$ pada Limbah Industri Pertambangan Emas, Journal of Chemical Process Engineering ISSN = 2303-3401 Vol.03, No.01, Mei 2018, Jurusan Teknik Kimia Fakultas Teknologi Industri Universitas Muslim Indonesia, Makassar

Kusuma IW, 2002, Alat Penurun Emisi Gas Buang pada Motor, Mobil, Motor Tempel dan Mesin Pembakaran Tak Bergerak, Jurnal Makara Teknologi Vol.6 No.3, Desember 2002, Program Studi Teknik Mesin, Universitas Udayana, Kampus Bukit Jimbaran, Bali

Morlok EK., 1995, Pengantar Teknik dan Perencanaan Transportasi, Erlangga, Jakarta.

Novita S, Sumantri W P and Budiharso H, 2015, Level of Gas Emissions of Passenger Car On Climb Road Segment, IOP Conf. Series: Earth and Environmental $\quad$ Science $\quad 179 \quad 012028$ https://iopscience.iop.org/article/10.1088/1755-1315/179/1/012028/pdf

Olivier G.J., et al, 2016, Trends In Global $\mathrm{CO}_{2}$ Emissions 2016 Report, PBL Netherlands Environmental Agency, Netherlands, http://edgar.jrc.ec.europa.eu/news_docs/jrc-2016-trends-in-global-co2emissions-2016-report-103425.pdf 
Peraturan Menteri Negara Lingkungan Hidup Nomor 12 tahun 2010 tentang Pelaksanaan Pengendalian Pencemaran Udara di Daerah

Sahputra F, Ramadhan GR, Nugroho A, 2019, Eco Filter Berbasis Zeolit sebagai Solusi Gas Buang pada Bahan Bakar Alternatif, Jurnal Universitas Negeri Yogyakarta, Yogyakarta

Sentiyaki, Astuti Andi, Fathurrahman I, dkk, 2018, Alat Penyaring Karbon Monoksida pada Knalpot Kendaraan Bermotor dengan menggunakan Adsorben Alami Ekstrak Daun Trembesi, Journal of Chemical Process Engineering ISSN = 2303-3401 Vol.03, No.01, Mei 2018, Jurusan Teknik Kimia Fakultas Teknologi Industri Universitas Muslim Indonesia, Makassar 